\title{
A Systems Thinking Approach to Corporate Strategy Development
}

\author{
Marion A. Weissenberger-Eibl ${ }^{1,2}$, André Almeida ${ }^{1, *}$ and Fanny Seus ${ }^{1, *}$ \\ 1 Department for Innovation and Technology Management (iTM), Institute for Entrepreneurship, Technology \\ Management and Innovation, (EnTechnon), Karlsruhe Institute of Technology (KIT), \\ Karlsruhe 76133, Germany; marion.weissenberger-eibl@kit.edu \\ 2 Fraunhofer Institute for Systems and Innovation Research ISI, Karlsruhe 76139, Germany \\ * $\quad$ Correspondence: andre.almeida@kit.edu (A.A.); fanny.seus@kit.edu (F.S.); Tel.: +49-(0)721-608-48959 (A.A.)
}

Received: 29 January 2019; Accepted: 5 March 2019; Published: 12 March 2019

check for updates

\begin{abstract}
In an increasingly complex business environment, companies need to reassess their strategic choices on a regular basis. However, companies are struggling to collect and efficiently interpret the relevant information on their business environment. Whereas market information is often analyzed, influences from the broader environment (e.g., society) are often neglected. This paper argues that companies often lack a systemic approach to their strategy development process, and that environmental influences are only considered selectively. We suggest that companies themselves need to be seen as systems that are embedded in a complex environment. To develop a successful strategic orientation, a systematic screening of the environment must be coupled with a thorough analysis of the firm's internal circumstances (e.g., competencies). Therefore, the paper proposes a holistic framework for conceiving companies as systems. Furthermore, we discuss how the scenario technique could support a systematic analysis of the company's environment. The paper also aims to provide practical guidelines for managers and contributes to integrating a systems thinking approach into strategy development.
\end{abstract}

Keywords: system theory; strategy development; strategic foresight; scenario technique; core competencies; strategic management

\section{Introduction}

In an increasingly complex business environment, companies need to reassess their strategic choices on a regular basis. Facing a world of growing global uncertainty and confusing complexity raises the question of how to manage these challenges. Strategic planning tries to provide companies with the tools they need to effectively prepare for constant environmental changes [1,2]. However, "because of the increasing rate of change in our environment and its uncertainty, both problems and their solutions have a decreasing life expectancy. For this reason, there is a greater need for decision-making systems that can learn and adapt rapidly than there is for optimizing systems that cannot" [3] (p. 357). Companies need to recognize "that the main problems of mankind are global, complex, nonlinear, and often random, too. [ . . ] Linear thinking and the belief that the whole is only the sum of its parts are evidently obsolete" [4] (p. 1).

In order to design adaptive decision-making systems, companies need to be able to deal with much information. Information-processing theory [5] suggests that more precise and accurate information should facilitate decision making. An information-processing view argues that organizations with a high capacity for processing information are better performers. There is a growing volume of case evidence that this relationship indeed holds true, at least in specific situations [6]. Performing complex tasks in a dynamic environment requires the processing of a greater amount of information, 
and therefore organizations should be designed to facilitate information processing [7,8]. However, companies are struggling to collect and efficiently interpret extensive information about their business environment. Whereas technological trends are often analyzed, influences from the broader environment (e.g., society) received less attention. Considering a larger number of different environmental influences proved to be an indicator for strong companies, as Tyssen et al. showed in their empirical study [9].

This paper argues that companies often lack a systemic approach to their strategy development process, and that environmental influences are only considered selectively. We suggest that companies themselves need to be seen as systems that are embedded in a complex environment. To develop a successful strategic orientation, systematic screening of the environment must be coupled with a thorough analysis of the firm's internal circumstances (e.g., competencies). Given the need for a systemic approach to strategic planning, the paper proposes a holistic framework for strategy development. Furthermore, we aim to provide practical guidelines for managers and contribute to integrating a systems thinking approach into strategy development.

This paper is structured as follows: First, we give an overview of how to think about companies as systems. Second, we develop a framework for integrating systems thinking into the strategy development process. This consists of two parts: A systematic analysis of the company's environment and a thorough investigation of the firm's internal potential. The paper also discusses how the scenario technique-a strategic planning method, which is used to anticipate changes in an organization's environment-can support a systematic analysis of the company's environment and proposes a structured approach to evaluating the company's competencies.

\section{The Firm and Its Environment: Seeing Companies as a System}

Systems theory distinguishes a system from its environment $[10,11]$. It is an alternative to the idea that things exist solely in isolation. Instead, systems theory assumes that something can only be understood if it is seen within a context (environment). That is, when talking about "something", there is at the same time something that distinguishes the first "something". Systems theory proves to be helpful when describing all kinds of systems (e.g., technical [12], social [13] or innovation systems [14-16]) regardless of their specific "nature" [17]. Systems theory enables us to deal with complexity and a large amount of knowledge. It is an interdisciplinary means of communication and permits analogy building between systems.

According to systems theory, a system consists of several elements (subsystems) that have attributes and interact with each other (see Figure 1). Due to interactions among elements, the system can have properties that its parts do not have. The system is delimited from the environment by a system boundary and interacts with the environment through inputs and outputs (e.g., information, material, energy, etc.). The function of a system can be described as the difference between the input and output variables [12,17].

This perspective can be applied to the strategic planning of a company, i.e., the company is seen as a system and its units (e.g., purchase, development, sales) as subsystems. The company is embedded in a complex environment (i.e., market, branch, politics, etc.), which determines its success. The difference between input and output variables is the value added by the company.

Including the company's environment is part of different strategic management concepts, e.g., SWOT analysis, Stakeholder Management or the St. Gallen Management model [18]. Hans Ulrich, a pioneer of systems-theory-oriented management in German-speaking countries, first published the latter. Another renowned author in this field is Michael Porter. He established the Five Forces approach for analyzing a business's competition [19]. Other approaches, such as the Learning Organization and Strategic Foresight consider that the company as well as the environment are undergoing continuous change. 


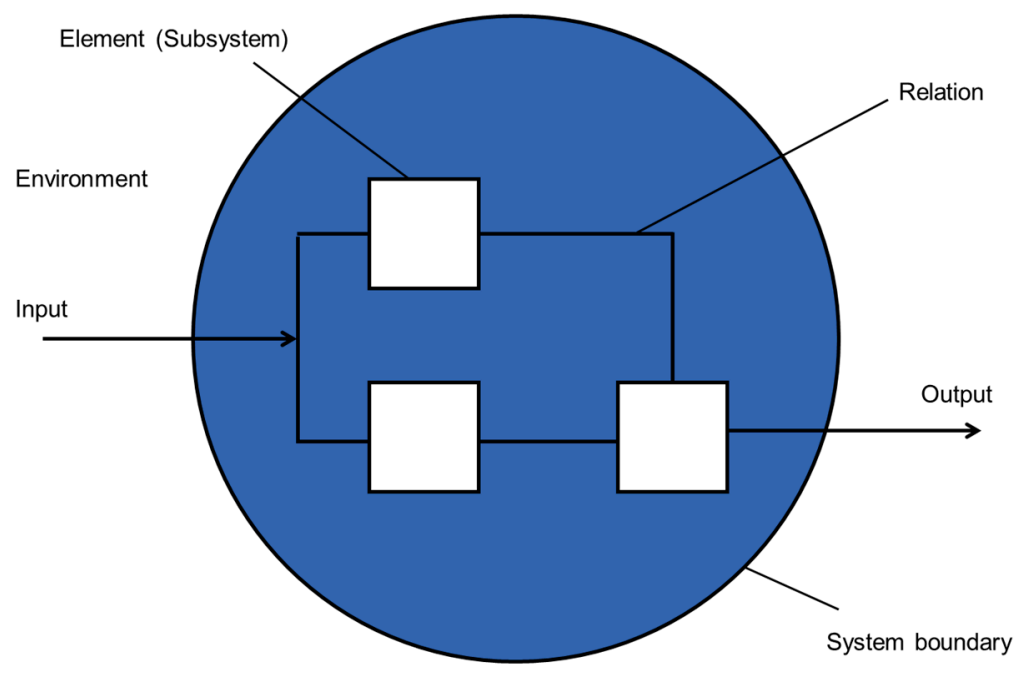

Figure 1. Basic elements of systems (own illustration).

"System-environment fit" and "intra-system fit" are crucial for a company's success (see Figure 2). System-environment fit means that the company's internal factors (e.g., competencies or resources) must be a good match for the external factors in the company's environment (e.g., customer demand or political requirements). For example, companies need to adjust their competencies according to customer needs so that they can achieve a competitive advantage in the market. Intra-system-fit means that all the internal aspects of the company (e.g., culture, strategy and processes) must be consistent, i.e., they need to contribute to each other and be aligned in a common direction. In the following sections we provide guidance on how to systematically analyze the firm and its environment, as well as how to adjust the company accordingly.

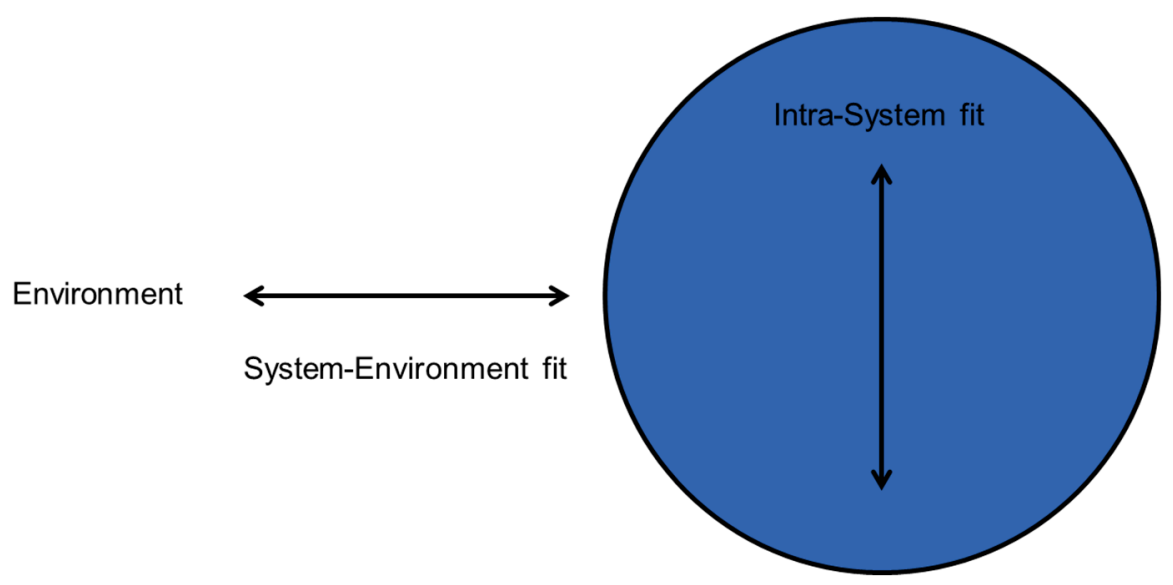

Figure 2. Internal and external fit (own illustration).

\section{A Systems Thinking Approach to Strategy Development}

Companies need to develop strategies that ensure their long-term competitive capacity, especially in turbulent environments [2]. However, managerial decisions can only be as good as the available information and the capacity of the decision-makers to process it. Companies therefore face two problems: First, in volatile environments, information is dispersed and changes rapidly. Second, the integration of behavioral decision theory into the strategic decision-making literature shows that the judgments of decision-makers in complex environments may be subject to systematic biases due to the rational limitations of the actors involved $[20,21]$. This applies in particular to the observation that individuals tend to stick with the status quo [22]. However, in a complex environment, it is 
essential for a firm's survival to adapt quickly and break away from old patterns. Applying a systemic approach is needed to overcome the limits of decision-making and information processing and to reduce biases in strategy development. In the following, we propose a methodical guidance for systematically collecting, analyzing and processing information about the environment and analyzing the internal competencies of the firm in order to properly prepare for decision-making. We argue that effective strategy development in complex environments is only possible by considering the external and internal system perspectives. They are both needed as prerequisites to strategy development. The strategy must build on the match between the internal factors of the firm (e.g., competencies, resources) and the external factors in its environment (e.g., customer demands, political requirements).

\subsection{Strategic Foresight and Scenarios: A Methodical Approach to Analyzing a Firm's Environment}

As discussed in Section 2 of this paper, the success of a company depends on how well it fits its environment. In today's complex business and market environment, it is hard for companies to maintain an overview and gather information about their continuously changing environments. Therefore, we want to provide guidance on how companies can systematically obtain information and track changes in their environments.

Strategic Foresight is a research field dealing with changes in a system's environment. Strategic Foresight can be defined as a set of tools, methods and processes that facilitate strategic decisions in an uncertain future $[23,24]$. We can distinguish foresight methods into those used for monitoring change (e.g., weak signals detection, trend management) and those used for thinking about possible futures (e.g., scenario technique, Delphi method). The application of foresight in the corporate context is often referred to in the literature as Corporate Foresight. Here, scholars analyze the ways in which companies can develop routines to systematically respond to external change $[25,26]$.

The scenario technique is an important method of Strategic Foresight. Scenarios illustrate multiple probable, plausible and possible futures, and can serve as the framework for strategic planning and decision-making. Scenarios try to draw holistic images of the future considering various aspects of today's world [24]. Robust strategies can be developed by analyzing scenarios. Furthermore, the scenario technique sensitizes mangers for possible changes in the environment, thus supporting prompt reactions $[26,27]$.

Some principles of the scenario technique are helpful for the systematic observation of the company's environment: First, in order to obtain a holistic view, the environment can be grouped into three holistic spheres of influence: Market, business and global environment, with an increasing distance to the company (see Figure 3). These spheres are interrelated, i.e., changes in the global environment affect the business and market spheres and vice versa. The connections and interrelations of these spheres depend on the specific case. These spheres can be further subdivided into fields of influence (e.g., supplier, customer or politics) (see Figure 3).

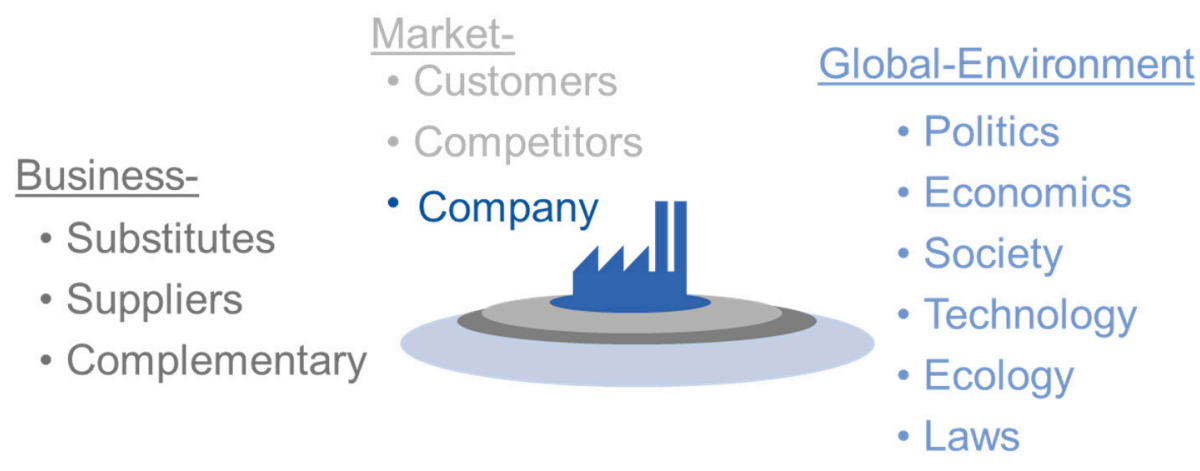

Figure 3. Subdivision of the environment in fields of influence (own illustration). 
Second, influencing factors that might have an impact on the specific strategic question involved are collected in each field. By collecting factors in each field, the dynamics of the company's environment is considered as a whole. At the same time, information is collected purposefully according to the specific strategic question addressed. As an example, let us assume our company is an OEM supplier producing powertrain components that is thinking about how electric mobility might change their business and if they should produce powertrain components for electric vehicles. In this case, influence factors are, amongst others, the mobility behavior in the society, the progress of battery development, and the charging infrastructure.

Third, the interdependencies between all the influencing factors are analyzed, for instance using pair-to-pair comparison in a dependency matrix, to answer two questions: How much does one factor influence the other, and how much is each factor influenced by the other? Continuing the previous case we would for example compare the two-influence factors "progress in materials research" and "progress in the development of battery cells". "Progress in materials research" has a high influence on "progress in the development of battery cells" but not the other way around. Those factors with the biggest overall influence are identified as the key influencing factors and are the most relevant ones for further actions and measures (e.g., standardization of electric powertrain components). On the other hand, those factors which are most influenced by others can be used to continuously monitor changes in the environment (e.g., image and acceptance of electric vehicles).

The systematic approach of the scenario technique offers several benefits to strategy development by mitigating biases in decision-making. First, it helps to reduce complexity: Influence factors are considered separately before taking into account the connections between them [28]. Second, it widens the search space for new opportunities and increases the likelihood for discovering potentially disruptive technologies. [29,30]. A continuous scanning activity not only helps to anticipate potential changes in the environment, but also allows the detection of 'weak signals', meaning trends that are less easy to perceive than mega trends [31]. The detection of weak signals is particularly relevant since it allows identifying underlying trends that might challenge the current business activities [29]. An example for weak signals in our example of an OEM supplier could be the increasing reports of small firms working on the development of electric cars starting from the early 2000s, e.g., the presentation of the car Venturi Fétish on the exhibition "Ever Monaco" or of the sports car Tesla Roadster in 2006.

Therefore, the scenario technique allows managers to widen their perspective in three ways: First, it shifts the perspective from short-term to long-term. Second, it draws attention from the current customers to other potential customer groups and future needs. Third, the scenario technique encourages one to envision multiple possible futures by contrasting different scenarios. By this, it helps reduce the status-quo bias of decision makers since it allows the systematic consideration of various options [28].

\subsection{Differentiation of Competencies: A Methodical Approach to Analyzing a Firm's Potential}

In order to survive in turbulent environments, companies need to maintain their competitive advantage. This advantage is based on distinctive strategic resources [32,33]. The term competence in the context of strategic management goes back to the so-called "resource-based view" [32]. According to Hamel and Prahalad, core competencies are a corporate-wide bundle of resources and capabilities that make a significant contribution to the customer benefits of the product and provide access to a wide variety of markets [33]. Core competencies are used across the organization and need to be maintained. They ensure the company's long-term competitive differentiation and market effectiveness (customer value or business value). Thus, they are to be understood as a source of sustainable competitive advantage and profitability.

However, a change in the environment can make resources that were once essential suddenly irrelevant [25]. Given the need to react to environmental changes, successful firms are those able to transform their strategic resources over time. This ability is described by Teece as a dynamic capability [34]. Companies often struggle to develop these dynamic capabilities. Therefore, we argue 
that, in strategy development processes, companies need to analyze the status quo of their capabilities first and then develop a roadmap for how their competencies need to evolve. In order to analyze the company's capabilities, one of the first steps is to become aware of the company's internal strengths and weaknesses and how important they are.

We propose using the competence model according to Wildemann to structure the different kinds of competencies [35]. This model is a strong analytical tool that allows not only the identification of current core competencies, but also the identification of strategic (dis)investments that lead to the development of future competencies [35] (see Figure 4).

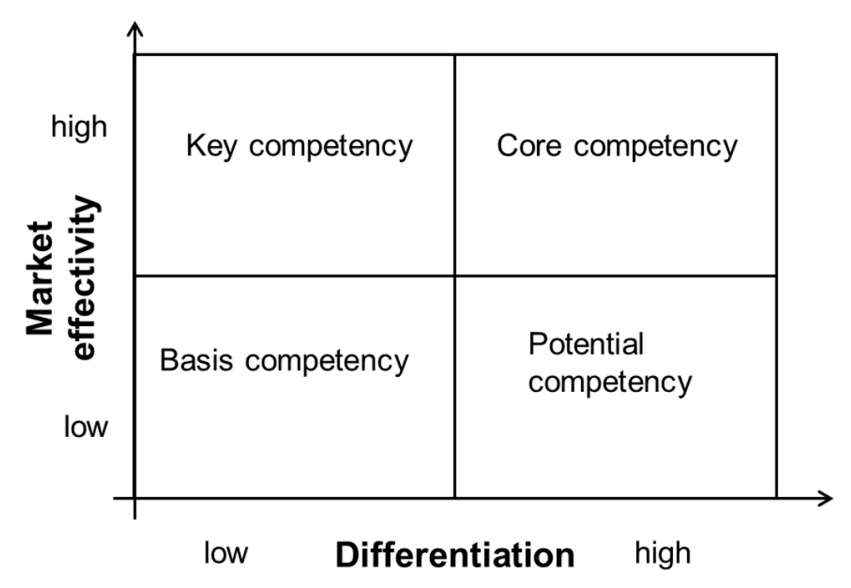

Figure 4. Competence model according to Wildemann (own illustration).

An important strength can be a key or core competence depending on its differentiation potential in the competition (quadrants at the top). Both have high market effectivity, i.e., value for the customer, but only core competencies are unique to the company. A core competence for an OEM supplier producing powertrain components might be the reliability of components. A key competence on the other hand, might be safety. Basic competencies are less important strengths. They have only low market effectivity and differentiation in competition, e.g., efficient cost management. Potential competencies are unique to the company but are not yet effective in the market, e.g., electrification.

The classification of competencies depends on market effectivity and differentiation in competition; both are determined by external factors in the company's market, business and global environment. For example, a change in the company's environment might lead to a core competency becoming a mere key competency if imitated by other competitors. A potential competency might become a core competency if the market situation changes. A company can only compete successfully in the market by formulating and implementing a strategy that has a good fit with its environment and leverages its unique portfolio of resources and capabilities. This is the reason why companies need to understand their own competencies and it is important to emphasize that competencies can change over time.

\section{A Holistic Model for Implementing Strategy in the Company}

In the previous section, we developed a systematic approach to systems thinking-based strategy development. This is an iterative process in which the strategy is refined by matching the internal and external perspective. A fast reaction to environmental changes is as important as the involvement of all stakeholders $[1,36]$. However, strategic planning not only includes strategy formulation but also strategy implementation and evaluation. Indeed, strategy implementation also poses a problem to organizations since managers lack practical models to guide their actions [1,37,38]. Managers often struggle to understand success factors of effective strategy implementation that are diverse and closely linked to one another. Hence, the need for comprehensive conceptual models for strategy implementation [1]. 
Strategy implementation affects the whole organization and can only be successful if implemented and followed in all parts of the organization. This means that the organizational structures and processes need to be adjusted to support the strategy [39]. Indeed, the main obstacles to strategy implementation are the process of managing the change and translating the new strategy into the company culture [40]. Again, systems thinking and a holistic approach can promote the adaptation of the company towards one common strategy. For this, we proposed a holistic framework according to Weissenberger-Eibl [15], which comprised all the relevant aspects of a company: Its organization, processes and methods as well as culture.

The framework defines seven fields of action (German: "Gestaltungsfelder"): In the middle, are the fields organization, processes, methods and human resources, through which all actions are coordinated. The field of technology surrounds the inner fields and supports the transfer of knowledge among actors and through all processes. The whole structure is embedded in leadership and culture. These shape the way the other fields are designed and actually practiced in everyday work. All the fields are highly interrelated and therefore, strategic actions must address all of them [15].

Continuing the previous case example of an OEM supplier producing powertrain components, a strategy based on the external and internal analysis might be a transformation towards a supplier producing electric powertrain components. Therefore, if we look at the human resources of the supplier some needed action would be to continuously increase the electric knowledge of their employees, for example by offering specific training or by hiring experts in this field. The supplier will also need to implement adequate processes (e.g., new logistics) and methods (e.g., specific testing for electric components) for producing electric powertrain components. And they will need to think about the kind of organizational structures that most fit their strategy.

When it comes to strategy implementation, managers often lack a full understanding of all the relevant factors that allow the diffusion of the strategy through all areas of the organization $[1,40]$. The framework proposed by Weissenberger-Eibl provides a holistic perspective and is a useful tool to successfully plan and implement a strategy, manage knowledge and transfer competencies. Managers need to make sure that the inner fields of actions in Figure 5: organization (i.e., organization design and structures needed to coordinate the new strategy), processes (i.e., operational structures and workflow management), methods (i.e., methods to generate new knowledge and develop new competence fields) and human resources (i.e., people with the experience and knowledge needed for the future and who are willing to adapt to changing environments) are addressed while implementing a strategy. Technology has to be used as a leverage to support the inner fields. In order to develop its full capacity, the strategy needs to be incorporated by leadership and culture. Both play an important role in the transmission of knowledge, as well as, the creation of a corporate understanding of the strategy [41].

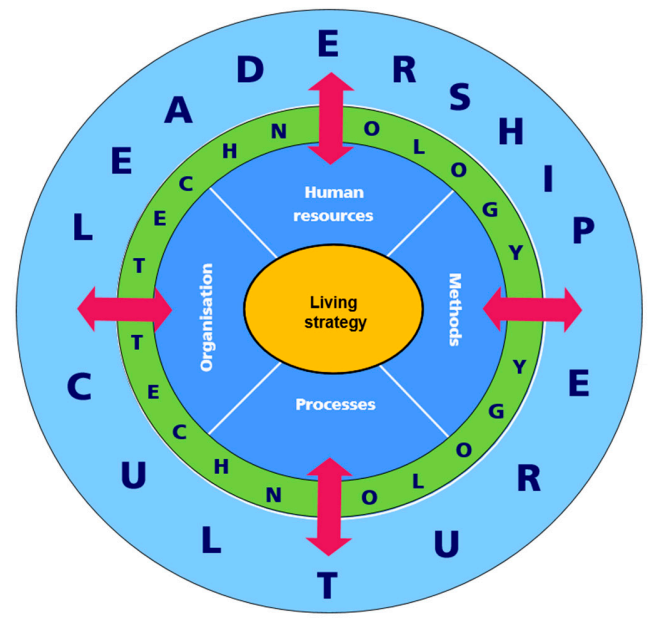

Figure 5. Holistic framework for successful strategy implementation (adapted from Weissenberger-Eibl/Koch 2013 [15], p. 100). 


\section{Conclusions}

In our paper, we developed a systemic approach to strategy development in complex environments. We argued that effective strategy development in complex environments is only possible when considering both the external and internal systems perspective of companies. For each perspective, we proposed a method to systematically generate input for strategy development: the scenario technique to analyze the external environment, and the competence model based on Wildemann for the internal assessment. These two methods address the external and internal analysis of the company and are the prerequisite for strategy development. A promising strategy is then the result of matching the internal competencies of the firm with the external requirements from the environment. Finally, the strategy needs to be implemented. In order to do so, again, a systemic perspective of the organization is needed. We proposed using the framework according to Weissenberger-Eibl; a holistic model of the fields to be considered. Figure 6 shows the overall framework that combines these three methods.

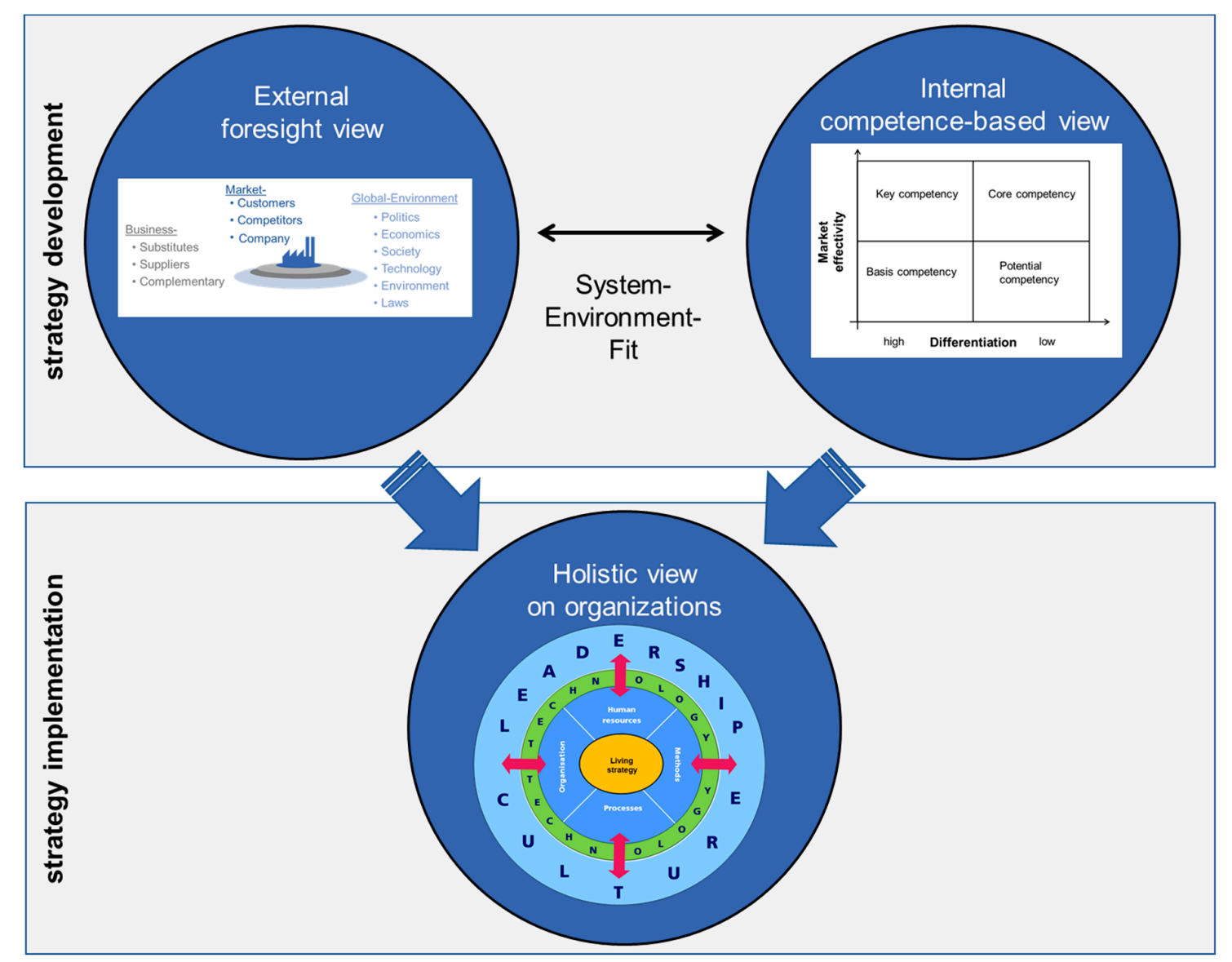

Figure 6. Holistic framework for a systemic approach of strategy development and implementation.

Combining these three methods results in a systematic approach to developing and implementing strategy in turbulent environments. With this work, we wanted to emphasize the need for systems thinking and holistic approaches in strategic management. For this, we provided an overall framework in which practical guidelines for managers can be embedded. Our contribution is conceptual in nature: First, we brought together the system-environment fit, as well as, the internal fit. Second, we proposed a holistic framework on how to move from strategy development to strategy implementation. This approach allows managers to overcome difficulties in decision-making related to information processing and offers a sound basis for the development of a viable strategy in a volatile environment. 
Author Contributions: Conceptualization, M.W., A.A. and F.S..; Writing-Original Draft Preparation, A.A. and F.S.; Writing-Review \& Editing, A.A. and F.S.; Visualization, A.A.; Supervision, M.W.

Funding: The author(s) received no specific funding for this work.

Acknowledgments: We acknowledge support by Deutsche Forschungsgemeinschaft and Open Access Publishing Fund of Karlsruhe Institute of Technology.

Conflicts of Interest: The authors declare no conflict of interest.

\section{References}

1. Kiliko, J.; Atandi, B.; Zachary, A. Strategic planning in turbulent environment: A Conceptual View. DBA Afr. Manag. Rev. 2012, 3, 73-89.

2. Grant, R.M. Strategic planning in a turbulent environment: Evidence from the oil majors. Strat. Mgmt. J. 2003, 24, 491-517. [CrossRef]

3. Ackoff, R.L. On the use of models in corporate planning. Strateg. Manag. J. 1981, 2, 353-359. [CrossRef]

4. Mainzer, K. Thinking in Complexity. The Computational Dynamics of Matter, Mind, and Mankind, 4th ed.; Springer: Berlin/Heidelberg, Germany, 2004; ISBN 9783662053669.

5. Blackwell, D. Equivalent Comparisons of Experiments. Ann. Math. Statist. 1953, 24, 265-272. [CrossRef]

6. Davenport, T.H.; Harris, J.G. Competing on Analytics. The New Science of Winning; Harvard Business School Press: Boston, MA, USA, 2007; ISBN 9781422103326.

7. Galbraith, J.R. Organization Design: An Information Processing View. Interfaces 1974, 4, 28-36. [CrossRef]

8. Galbraith, J.R. The Future of Organization Design. J. Org. Des. 2012, 1, 3. [CrossRef]

9. Tyssen, M.; Schneider, C.; Gleich, R.; Wald, A. Corporate Foresight in kleinen und mittleren Unternehmen. ZfKE Z. KMU Entrep. 2012, 60, 1-28. [CrossRef]

10. Maani, K.E.; Cavana, R.Y. Systems Thinking and Modelling. Understanding Change and Complexity, Repr; Pearson Education: Albany, NY, USA, 2004; ISBN 9781877258008.

11. Richmond, B. An introduction to systems thinking. Ithink software; High Performance Systems: Hanover, NH, USA, 2001; ISBN 9780970492104.

12. Ropohl, G. Allgemeine Technologie: Eine Systemtheorie der Technik; Univ.-Verl. Karlsruhe: Karlsruhe, Germany, 2009; ISBN 9783866443747.

13. Luhmann, N. Soziale Systeme. Grundriß Einer Allgemeinen Theorie; Suhrkamp Verlag: Berlin, Germany, 1987; ISBN 3518282662.

14. Weissenberger-Eibl, M.A. Innovationsforschung-ein Systemischer Ansatz.: Merkmale, Methoden und Herausforderungen. In Denkströme Heft 17; Präsident der Sächsischen Akademie der Wissenschaften zu Leipzig; Leipziger Universitätsverlag: Leipzig, Germany, 2017; pp. 33-56.

15. Weissenberger-Eibl, M.A.; Koch, D.J. Innovation-Technologie-Entrepreneurship. Gestaltungssystem der frühen Phase des Innovationsprozesses; Cactus-Group-Verl.: Karlsruhe, Germany, 2013; ISBN 978-3-937289-11-3.

16. Weissenberger-Eibl, M.A.; Koch, D.J. Innovationssysteme in Mittel- und Osteuropa. Akteure, Aktionsfelder, Länderprofile; Cactus-Group-Verl.: Kassel, Germany, 2007; ISBN 9783937289045.

17. Mele, C.; Pels, J.; Polese, F. A Brief Review of Systems Theories and Their Managerial Applications. Serv. Sci. 2010, 2, 126-135. [CrossRef]

18. Rüegg-Stürm, J. Das neue St. Galler Management-Modell. Grundkategorien einer Modernen Managementlehre; Haupt: Bern, Switzerland, 2007; ISBN 978-3-258-06629-5.

19. Porter, M.E. Towards a dynamic theory of strategy. Strateg. Manag. J. 1991, 12, 95-117. [CrossRef]

20. Tversky, A.; Kahneman, D. Rational Choice and the Framing of Decisions. J. Bus. 1986, 59, S251. [CrossRef]

21. Liu, G.; Harris, S. Group Conflicts and Faultlines: The Behavioural Dynamics of Top Management Teams. In Proceedings of the EURAM 2018 Conference, Reykjavík, Iceland, 19-22 June 2018.

22. Samuelson, W.; Zeckhauser, R. Status quo bias in decision making. J. Risk Uncertain. 1988, 1, 7-59. [CrossRef]

23. Müller, A.W.; Müller-Stewens, G. Strategic Foresight. Trend- und Zukunftsforschung in Unternehmen-Instrumente, Prozesse, Fallstudien; Schäffer-Poeschel Verlag: Stuttgart, Germany, 2009; ISBN 9783791028682.

24. Fink, A.; Siebe, A. Handbuch Zukunftsmanagement. Werkzeuge der strategischen Planung und Früherkennung; Campus-Verl.: Frankfurt am Main, Germany, 2006; ISBN 9783593378046. 
25. Rohrbeck, R. Corporate Foresight. Towards a Maturity Model for the Future Orientation of a Firm; Physica-Verlag: Berlin, Germany, 2011; ISBN 9783790826265.

26. Tyssen, M. Zukunftsorientierung und dynamische Fähigkeiten. Corporate Foresight in Unternehmen der Investitionsgüterindustrie; Springer Gabler: Wiesbaden, Germany, 2012; ISBN 9783834938954.

27. Postma, T.J.B.M.; Broekhuizen, T.L.J.; van den Bosch, F. The contribution of scenario analysis to the front-end of new product development. Futures 2012, 44, 642-654. [CrossRef]

28. Gausemeier, J.; Plass, C. Zukunftsorientierte Unternehmensgestaltung. Strategien, Geschäftsprozesse und IT-Systeme für die Produktion von morgen, 2., überarb. Aufl.; Hanser: München, Germany, 2014; ISBN 978-3-446-43842-2.

29. Rohrbeck, R. Trend Scanning, Scouting and Foresight Techniques. In Management of the Fuzzy Front End of Innovation; Gassmann, O., Schweitzer, F., Eds.; Springer: Cham, Switzerland, 2014; pp. 59-73. ISBN 978-3-319-01055-7.

30. Drew, S.A.W. Building technology foresight: Using scenarios to embrace innovation. Eur. J. Innov. Manag. 2006, 9, 241-257. [CrossRef]

31. Ansoff, H.I. Managing Strategic Surprise by Response to Weak Signals. Calif. Manag. Rev. 1975, 18, 21-33. [CrossRef]

32. Penrose, E.T. The Theory of the Growth of the Firm, 4th ed.; Oxford University Press: Oxford, UK, 2009; ISBN 9780199573844.

33. Hamel, G.; Prahalad, C.K. Competing for the Future, [Nachdr.]; Harvard Business School Press: Boston, MA, USA, 2007; ISBN 9780875847160.

34. Helfat, C.E.; Finkelstein, S.; Mitchell, W.; Peteraf, M.A.; Singh, H.; Teece, D.J.; Winter, S.G. Dynamic Capabilities: Understanding Strategic cHange in Organizations; Blackwell Publishing: Malden, MA, USA; Oxford, UK, 2007; ISBN 978-1-4051-8206-5.

35. Wildemann, H. Innovationsmanagement. Leitfaden zur Einführung eines effektiven und effizienten Innovationsmanagementsystems; 17. Auflage 2017; TCW Transfer-Centrum Verl.: München, Germany, 2017; ISBN 978-3-931511-94-4.

36. Camillus, J.C. Strategy as a Wicked Problem. Harv. Bus. Rev. 2008, 86, 98-106.

37. Mintzberg, H.; Ahlstrand, B.W.; Lampel, J. Strategy Safari. The Complete Guide through the Wilds of Strategic Management, 7th ed.; FT Prentice Hall Financial Times: Harlow, UK; London, UK; New York, NY, USA; Boston, MA, USA; San Francisco, CA, USA; Toronto, ON, Canada, 2009; ISBN 9780273719588.

38. Raps, A. Strategy implementation-An insurmountable obstacle? Handb. Bus. Strateg. 2005, 6, 141-146. [CrossRef]

39. Sterling, J. Translating strategy into effective implementation: Dispelling the myths and highlighting what works. Strateg. Leadersh. 2003, 31, 27-34. [CrossRef]

40. Hrebiniak, L.G. Obstacles to Effective Strategy Implementation. Organ. Dyn. 2006, 35, 12-31. [CrossRef]

41. Weissenberger-Eibl, M.A.; Spieth, P. Knowledge Transfer: Affected by Organisational Culture? In Proceedings of the 6th International Conference on Knowledge Management (I-Know '06), Graz, Austria, 6-8 September 2006; Tochtermann, K., Maurer, H., Eds.; Know-Center: Graz, Austria, 2006; pp. 68-75. 